\title{
Patterns and predictors of adolescent life change during the COVID-19 pandemic: a person-centered approach
}

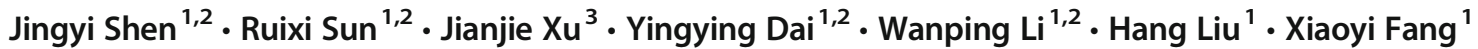

Accepted: 5 August 2021 / Published online: 13 September 2021

(C) The Author(s), under exclusive licence to Springer Science+Business Media, LLC, part of Springer Nature 2021

\begin{abstract}
The present study investigated patterns of adolescent life changes across multiple life domains and utilized a holistic-interactionistic perspective to examine their individual, familial, and societal correlates with a sample of 2544 Chinese parent-adolescent dyads. Adolescents were aged from 10 to 19 years old $(50.16 \%$ girls). Latent profile analysis revealed five life change profiles, including three improved profiles at various degrees, one unchanged profile, and one worsened profile. The majority of adolescents had an improved or unchanged life. Multinomial logistic regression analyses found that most of the individual, familial, and societal factors predicted the group memberships. Notably, parent-adolescent conflict was a significant factor that predicted memberships of all patterns. These findings show the resilience of adolescents and indicate the need for policies and interventions that consider the holistic nature of adolescents' person-context system, especially during a global crisis such as the COVID-19 pandemic.
\end{abstract}

Keywords Life change $\cdot$ Adolescent $\cdot$ Individual level $\cdot$ Familial level $\cdot$ Societal level $\cdot$ COVID-19

Brought by some unexpected events, life changes can lead to a better or worse life (Haslam et al., 2020). As an acute event, the COVID-19 pandemic has drawn us in the midst of a global crisis, projecting humanity into an unprecedented era which was different from the one we have been facing for more than a century. This ongoing crisis has been consistently posing considerable influences on all segments of the population. According to life-course profiles in life-span perspective, the role of history-graded events (e.g., COVID-19 pandemic) is particularly strong for adolescents (Baltes et al., 1980). Yet, adolescents have received scarce attention. The limited work focusing on adolescents mainly illustrated the negative impacts of the pandemic (Brooks et al., 2020; Ravens-Sieberer et al., 2021; Xiang et al., 2020). However, scholars also suggested that when some people fare worse, others fare better in the face of an unprecedented threat (Morgeson et al., 2015). Some researchers took a further step and identified that the

Xiaoyi Fang

fangxy@bnu.edu.cn

1 Institute of Developmental Psychology, Beijing Normal University, No. 19 Xin Jie Kou Wai Street, Hai Dian District, Beijing 100875, China

2 Research Center for High School Student Developmental Guidance, Beijing Normal University, Beijing, China

3 Faculty of Psychology, Beijing Normal University, Beijing, China pandemic might bring variant changes in different domains of life (Wang et al., 2021), indicating the importance of identifying different patterns of life changes across various life domains with a person-centered approach.

In addition to mapping distinct profiles, it is also essential to examine the factors that distinguish different profiles. Adolescents live in multiple contexts, characteristics of which contribute to their adjustment (Bronfrenbrenner, 1979). From a holistic-interactionistic perspective, it is important to consider both individual and environmental factors in influencing adolescent development. However, recent studies mostly examined unidimensional influence (e.g., only considering individual, familial, or societal factors) on adolescent life during the pandemic (e.g., Prime et al., 2020; Xu et al., 2020).

To address these gaps, we focused on changes of personal (emotion, academic, regularity) as well as interpersonal (relationship among family members) domains and explored how their combinations would define experiences for different people. Drawing upon a holisticinteractionistic perspective, we proceeded to examine multi-level factors that predict life change patterns to discover factors that can reduce negative or promote positive effects of this macro crisis. This study may provide important insight in identifying adolescents who are at greatest risk for negative life change and examining factors that are crucial for promoting life quality or preventing from a worsened life during unprecedented situations. 


\section{The Heterogeneous Impact of COVID-19 on Adolescents}

Adolescents are especially susceptive to historic events (Baltes et al., 1980), such as the COVID-19 pandemic. Recent studies have shown that either a student status (C. Wang, Pan, Wan, Tan, Xu, Ho et al., 2020) or a younger age (C. Wang, Pan, Wan, Tan, Xu, McIntyre et al., 2020) is associated with a worse mental health status during the initial phase of the COVID-19 pandemic, indicating that adolescents might be more influenced by the pandemic than older adults. The COVID-19 pandemic and accompanying prevention measures have deeply affected the lives of countless adolescents (G. Wang et al., 2020). For example, school closures changed adolescents' life routines and limited their activity by changing their main arena from school to home. During the over-two-month home confinement, family became the main context where adolescents slept, ate, learned, and practiced sports (Amerio et al., 2020). Taking advantage of this occasion, interaction and bonds within some families might be enhanced (G. Wang et al., 2020), while for those adolescents in a time of "storm and stress" (Hall, 1904), the increased contact with their parents may not be a pleasant experience.

Up till now, the limited work focusing on adolescents mostly revealed negative impacts of the pandemic on various aspects of their lives, including emotion, academic, regularity, and social interactions. Specifically, adolescents experienced more negative emotions such as fear, boredom, and frustration (Brooks et al., 2020), reported more academic challenges including less concentration and confidence in remote learning (Becker et al., 2020; Putri et al., 2020), accompanied by more leisure screen time and less physical activity (Xiang et al., 2020) during the pandemic. In addition to personal aspects, the pandemic also affected adolescents' interactions with others. Their quantity and quality of social interactions as well as outdoor activities reduced sharply (Hawke et al., 2020). Challenges of interactions among family members have also been risen up after the implementation of home confinement policy due to the economic pressure and increasing time spent at home with family members (Prime et al., 2020; Russell et al., 2020).

However, the pandemic did not necessarily bring negative effects. Acute adversity (e.g., the global pandemic) might trigger an improvement in psychological and social functioning in a subset of people. As Mancini (2020) advocated, "we should not lose sight of the ways the pandemic may positively impact social and psychological functioning". With regard to the mechanism, the Psychosocial Gains from Adversity (PGA) proposed that adversity stimulates automatic social-affiliative and prosocial behaviors. As a result, both individual relationships and individual functioning get promoted (Mancini, 2019). Indeed, recent research offered initial evidence. A nationwide cross-sectional study of Chinese citizens from 34 provinces found that a small proportion of participants displayed healthier eating habits and better sleep quality during the home-confinement period, which contributed to a better health-related quality of life (X. Wang et al., 2020). A longitudinal study also found no change in depression and rumination, and even decrease in anxiety after the pandemic (Katz \& Yovel, 2020).

Some researchers went a step further and proposed that the pandemic might bring variant changes to different domains of life. For example, Wang et al. (2021) found that people perceived more social support from others after the pandemic even though they suffered sharp decrease of well-being simultaneously. In addition, another study found an increase in negative emotions yet a decrease in sleep problems during the pandemic ( $\mathrm{Li}$ et al., 2020). Since individuals react differently to the pandemic, and individual's life is composed by various domains, it is likely that the pandemic brings variant patterns of life changes among different people. As such, adopting a person-centered approach is necessary.

Due to lack of knowledge about how the COVID-19 crises impact adolescent comprehensively, the first aim of the present study is to explore the heterogeneous consequences of the COVID-19 on five domains of adolescent life (interparental relationship, parent-adolescent relationship, emotional state, academic state, and regularity of life) using a person-centered approach.

\section{A Holistic-Interactionistic Perspective}

In addition to identifying change patterns, it is also crucial to examine factors that predict the change patterns. The holistic-interactionistic perspective (Magnusson \& Stattin, 2006) emphasized that individual functioning could be described as an integrated, complex, and dynamic process, which is characterized by continuously ongoing interactions between the individual and the environment. Considering individuals as active and purposeful agents who can perceive, interpret, and react to information from the external world, the holistic-interactionistic perspective proposed that both individual and environmental factors are pivotal for individual development. Typically, family, school, and society contexts are considered to play the most important roles in adolescent development. However, due to the home-confinement policy during the special global pandemic period, the school environment became less important. Adolescents left school to take online courses so that the effects from school, teacher, and peers were largely reduced. Hence, the present study mainly considered family and society contexts. 


\section{Individual Level}

As active agents, individual factors are influential to one's own development both physically and mentally during the COVID-19 pandemic (Harper et al., 2020; Li et al., 2020). The extant literature has identified several demographic risk factors associated with negative life changes for adolescents: female compared to male (Li et al., 2020); older people compared to younger people (Qiu et al., 2020). In addition to these biological aspects, the pandemic may also trigger emotional and behavioral coping, including psychological distress, fear of the COVID-19, and help-seeking behaviors (Ornell et al., 2020; Shigemura et al., 2020; Wang, Pan, Wan, Tan, Xu, Ho et al., 2020). Help-seeking behaviors, referring to reading articles related to psychological self-help, watching or listening to psychological online training video or audio, dialing psychological assistance hotline, etc., is a generally advocated behavioral strategy to cope with difficulties during public health emergencies (Luo et al., 2020). Research has found that all these COVID-19 related individual factors affected people's life, indicating that less COVID-19 fear and psychological distress (Satici et al., 2020) and more help-seeking behaviors (Barros et al., 2020) were associated with better lives. Thus, individual-level factors - gender, age, fear of COVID19 , psychological distress, and help-seeking behaviors - identified from the literature may be associated with adolescent life changes.

\section{Familial Level}

Parental Factors As an active and integrated part in the family system, parents play an important role in influencing adolescent development (Magnusson \& Stattin, 2006). During this crisis, higher parental education was proved as an effective protective factor for individual functioning (Wanberg et al., 2020). Moreover, previous research indicated that parents' and adolescents' mental health are closely intertwined (Crum \& Moreland, 2017). Recent research also supported this view by finding that higher levels of parental depressive symptoms and stress (Whittle et al., 2020), and lower levels of parent support-seeking (Drouin et al., 2020) were related to higher levels of child mental health status during this time of crisis. As such, the present study also included parental demographics (education) and their reactions (fear of COVID-19, psychological distress, and help-seeking behaviors) towards COVID-19 when predicting adolescent life changes.

Family Interactions The holistic-interactionitic perspective emphasized dyadic interactions between family members (Magnusson \& Stattin, 1998), including parent-adolescent and interparental interactions. Parent-adolescent conflict and interparental conflict (i.e., marital conflict) were widely used to reflect negative interactions of family members (Chaplin et al., 2012; Zemp et al., 2019). In addition, both conflicts usually coexist and have additive effects on adolescent (Bradford et al., 2008). Specifically, previous research found that parentadolescent conflict was related to poor social and psychological adjustment such as depression and aggression in adolescents (Bámaca-Colbert et al., 2012; Steeger \& Gondoli, 2013). Likewise, research revealed that marital conflict (i.e., interparental conflict) was also related to heightened antisocial behavior and depression (Bradford et al., 2008) and decreased well-being (Davies et al., 2002). Thus, parent-adolescent conflict and interparental conflict/marital conflict were both used to examine the impact of family interactions on the changes in adolescent life.

General Family Climate In addition to parental correlates and dyadic interactions, researchers also advocated the necessity to consider the influence of the overall family climate on adolescent development (Hinde, 1992; Minuchin, 1985). Evidence from previous research has demonstrated that although both dyadic interactions and general family environment influenced child adjustment (Browne et al., 2015), the latter had unique explanatory power above the former (Johnson et al., 1999; Richmond \& Stocker, 2006). Specifically, family economic status (Ermisch \& Francesconi, 2001) and living space (Amerio et al., 2020) are commonly used indicators for family economic background, while family chaos (Butcher \& Plomin, 2008) is a typical measure of family functioning, all of which can reflect the whole family climate. According to existing evidence in adolescence, lower family income could predict worse psychological and academic status (Davis-Kean, 2005; Shapero \& Steinberg, 2013), and the limited living space could predict poor mental health and low quality of life (Ravens-Sieberer et al., 2021). Moreover, a review on family chaos concluded its negative effects on adolescent academic development, socioemotional well-being, and mental and physical health (Marsh et al., 2020). Jointly, the present study considered family economic status, per capita living space, and home chaos as indicators of the whole family climate and discovered their influences on adolescent life changes.

\section{Societal Level}

As the holistic-interactionistic perspective mentioned, proximal environment is embedded in economic, social, and cultural systems of a higher order, and individual development is determined by formal societal rules. Faced with the pandemic, most countries' governments have implemented massive antiepidemic measures, such as controlling mobility, suspending public facilities and venues (e.g., bars, cinema), etc. As such, societal rules had been largely adjusted to cope with the public health crisis. In addition to the inhibitory measures, the Chinese government also mobilized national supplies, 
providing basic necessities for high-risk areas and psychological services for the whole country. Furthermore, some activities such as charitable donation and voluntary service emerged in communities, so that the public perceived much support from the government (Chen et al., 2020). As a result, various forms of social support perceived by Chinese parents and adolescents is likely to serve as a positive resource which can protect them from maladaptive life changes (Cao et al., 2020).

Considering co-existence of these multi-level influences, the holistic-interactionistic perspective suggests that a multivariate strategy should be applied to examine integrated influences of multiple factors on adolescent development (Magnusson \& Stattin, 2006). Combined with prior research, we proposed a three-level model revealing multiple influences on adolescent life, including individual, familial (parental factors, family interactions, and general family climate), and societal levels of influences (see Fig. 1).

\section{The Present Study}

Adopting the holistic-interactionistic perspective, the current study aimed to (a) examine the patterns of adolescent life change during the pandemic, and (b) test whether and how influential factors at individual, familial, and societal level predict these patterns. According to the PGA, it was hypothesized that there might be three patterns of adolescent life changes: improved, worsened, and unchanged. Based on theoretical and empirical findings, the majority of targeted predictors at all three levels were hypothesized to distinguish different patterns.

\section{Methods}

\section{Participants and Procedures}

Data for the study were drawn from a large-scale program called Family Relationship Survey and Intervention between April 10th and May 10th, 2020, when the country was under a partial lockdown and the students were in the process of going back to school orderly. This program was approved by the institutional ethical committee of authors' host university. All families were recruited via network and school promotion. Families that fulfilled the following inclusion criteria were selected (1) at least one child was in grade 4 and above; (2) the child cohabited with at least one parent. Informed consent was obtained from all adolescents and their parents participated.

A total of 3881 parents and 2544 adolescents (4-12 grades) from four provinces of China engaged in our
Fig. 1 Conceptual model of multiple influences on adolescent life from the holistic-

interactionistic perspective

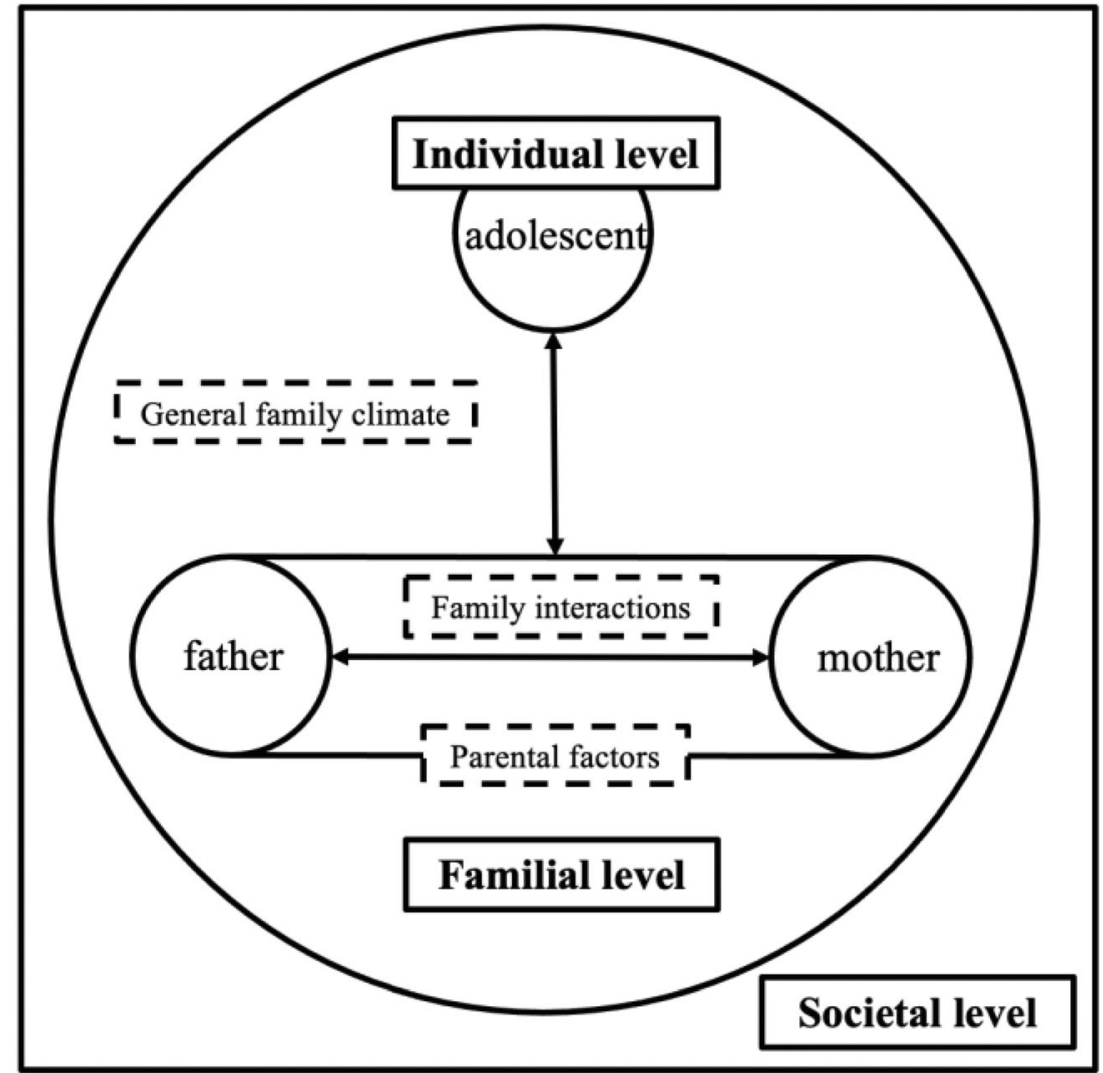


study. The current study used a subsample of 2544 matching parent-adolescent dyads from the original dataset. The ages of adolescents ranged from 10 to 19 years old $(M=13.93, S D=2.05)$. Per capita living area of the participants' family varied from 6 to 175 square meters $(M=28.87, S D=15.99)$. Characteristics of total sample were shown in Table 1 .

\section{Measures}

Predictors at Three Levels Each of the substantive scales of predictors used in the current study provided in Table 2.

Life Changes Adolescents' life changes before and after the COVID-19 pandemic was measured by a self-designed scale. Adolescents were asked to rate their status during the pandemic compared with pre-pandemic in five aspects (interparental relationship, parent-adolescent relationship, emotional status, academic status and regularity of life) on a 5 -point scale $(1=$ much worse to $5=$ much better $)$. A sample item is "In general, what do you think of your relationship with your parents during the pandemic compared with pre-pandemic?" A score higher than 3 in a certain domain represents improvement in that domain of life and vice versa. The Cronbach's $\alpha$ was .92 in the present study. The construct validity was examined using confirmatory factor analysis (CFA), and an adequate fit to the data was revealed $(\mathrm{CFI}=.998, \mathrm{TLI}=.995$, RMSEA $=.045$, SRMR $=.006$ ).

All instruments demonstrated full or partial metric invariance across three educational stages, indicating the measurements could be used for all ages.

\section{Analytic Strategy}

\section{Latent Profile Analysis}

Latent Profile Analysis (LPA) was conducted with Mplus 8.3 to identify the number of latent profiles regarding the change patterns of adolescents' life before and after the outbreak of the pandemic. LPA is a person-centered statistical approach
Table 1 Characteristics of study participants

\begin{tabular}{|c|c|c|c|c|}
\hline & \multicolumn{2}{|c|}{ Adolescents } & \multicolumn{2}{|c|}{ Parents } \\
\hline & $n$ & $\%$ & $n$ & $\%$ \\
\hline \multicolumn{5}{|l|}{ Gender } \\
\hline Female & 1276 & 50.16 & 1904 & 74.80 \\
\hline Male & 1268 & 49.85 & 641 & 25.20 \\
\hline \multicolumn{5}{|l|}{ Educational stage } \\
\hline Primary school (4-6 grades) & 707 & 27.79 & & \\
\hline Middle school & 1158 & 45.52 & & \\
\hline High school & 679 & 26.69 & & \\
\hline \multicolumn{5}{|l|}{ Highest level of education } \\
\hline Middle school or lower & & & 1033 & 40.61 \\
\hline High school & & & 858 & 33.73 \\
\hline Junior college or bachelor degree & & & 637 & 25.04 \\
\hline Master degree or higher & & & 16 & 0.63 \\
\hline \multicolumn{5}{|l|}{ Perceived family economic status } \\
\hline Much worse & 44 & 1.73 & & \\
\hline Worse & 281 & 11.05 & & \\
\hline Almost the same & 1946 & 76.49 & & \\
\hline Better & 238 & 9.36 & & \\
\hline Much better & 35 & 1.38 & & \\
\hline \multicolumn{5}{|l|}{ Annual household income } \\
\hline Less than 50,000 RMB (about $\$ 7685$ ) & & & 879 & 34.55 \\
\hline 50,000 RMB - 100,000 RMB (about $\$ 7685$ to $\$ 15,370$ ) & & & 1012 & 39.78 \\
\hline $100,000 \mathrm{RMB}-200,000 \mathrm{RMB}$ (about $\$ 15,370$ to $\$ 30,740$ ) & & & 487 & 19.14 \\
\hline $200,000 \mathrm{RMB}-400,000 \mathrm{RMB}$ (about $\$ 30,740$ to $\$ 61,480$ ) & & & 129 & 5.07 \\
\hline More than 400,000 RMB (about $\$ 61,480$ ) & & & 37 & 1.45 \\
\hline
\end{tabular}

Note: $N=2544.94 .58 \%$ of parents participated were main caregivers 


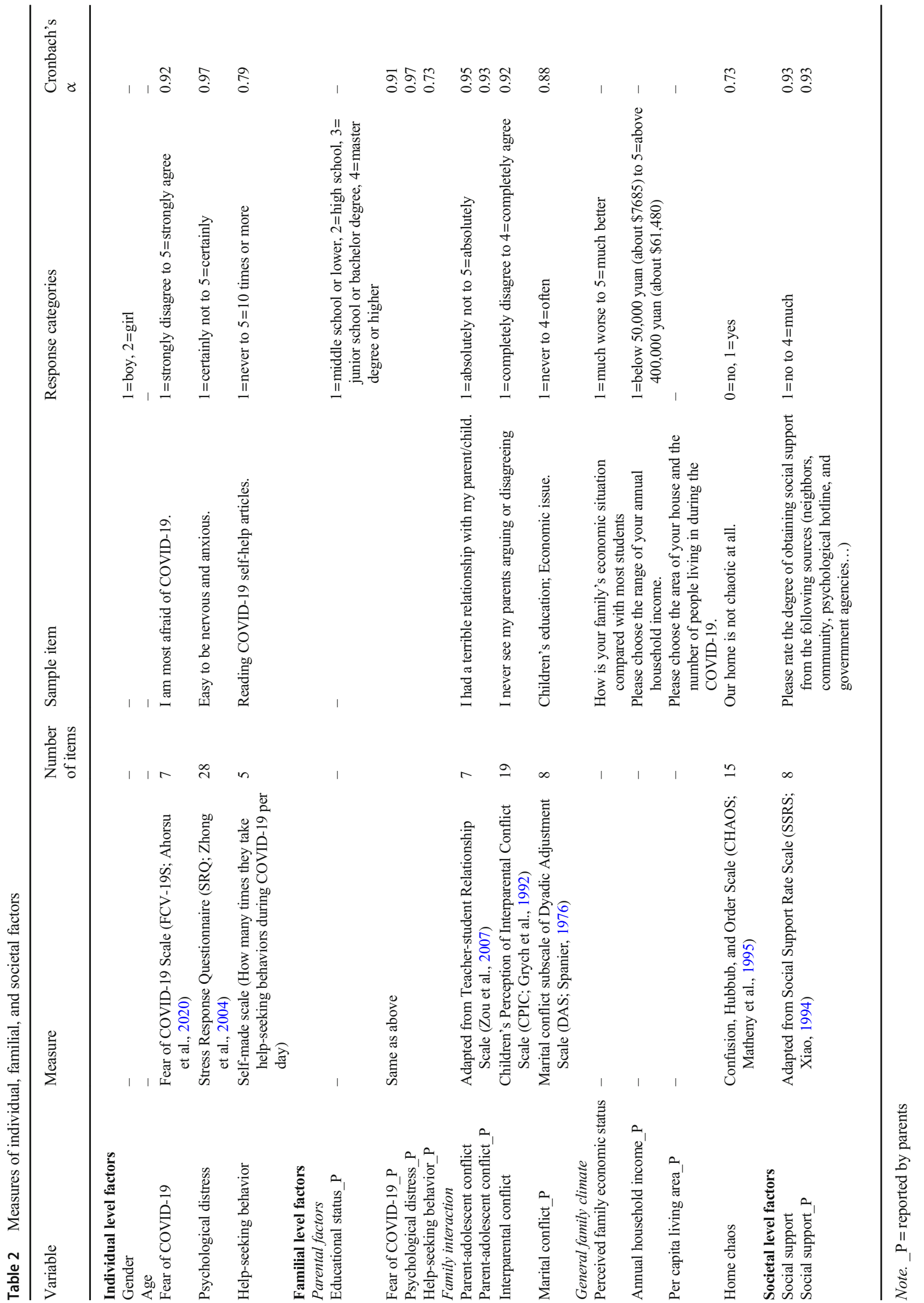


aimed at identifying latent subgroups with similar patterns of variables. This method could detect profiles that differ qualitatively or quantitatively in combinations of continuous observed variables, discovering hidden groups from them (Giano et al., 2020; Woo et al., 2018).

In order to identify the optimal number of profiles, we depended on a combination of multiple fit indices. A better fitting model included Lower LL, AIC, BIC, aBIC, higher entropy, and significant LMRT and BLRT (Collins \& Lanza, 2010). In addition, class prevalence, parsimony, and interpretability (percent of participants interpreted and unique information provided by an additional class) were also considered when determining the optimal profiles (Jung \& Wickrama, 2008).

\section{Multinomial Logistic Regression}

To examine the associations between hypothesized predictors and profiles, a series of multinomial logistic regressions were conducted to assess whether increase/decrease in a certain predictor would result in a higher/lower probability that a participant belongs to one profile over another. R3STEP option in Mplus was used for the following advantages compared to traditional multinomial logistic regression. Firstly, instead of assigning a $100 \%$ probability that each participant is divided into a certain profile, most likely class membership was obtained based on the posterior distribution in R3STEP so that profile probabilities (i.e. the probability of an individual being in each profile) were took into consideration (Asparouhov \& Muthén, 2014; Vermunt, 2010). Besides, R3STEP could reduce biased estimates for the covariate effects because the auxiliary variables are assessed after determining the best profile solution (Gudicha \& Vermunt, 2013).

Based on these advantages, all predictors were entered into regression analyses simultaneously. If reported odd ratios (ORs) are greater than 1, the probability of being classified into a particular profile (rather than a reference profile) will increase along with every unit of increase in the predictor variable.

\section{Results}

\section{Latent Profile Analysis}

Table 3 shows the fit indices for one-to-eight profile solution. The five-profile solution was chosen as the "optimal" because: (1) this solution had relatively lower AIC, BIC, and aBIC values as well as the second highest entropy; (2) the significant $p$ value on the LMR and BLRT suggested that the fiveprofile solution had a better fit than the four-profile solution which had the highest entropy; and (3) solutions with six and more than six profiles yielded profiles with extremely small subgroup size (less than 5\%).

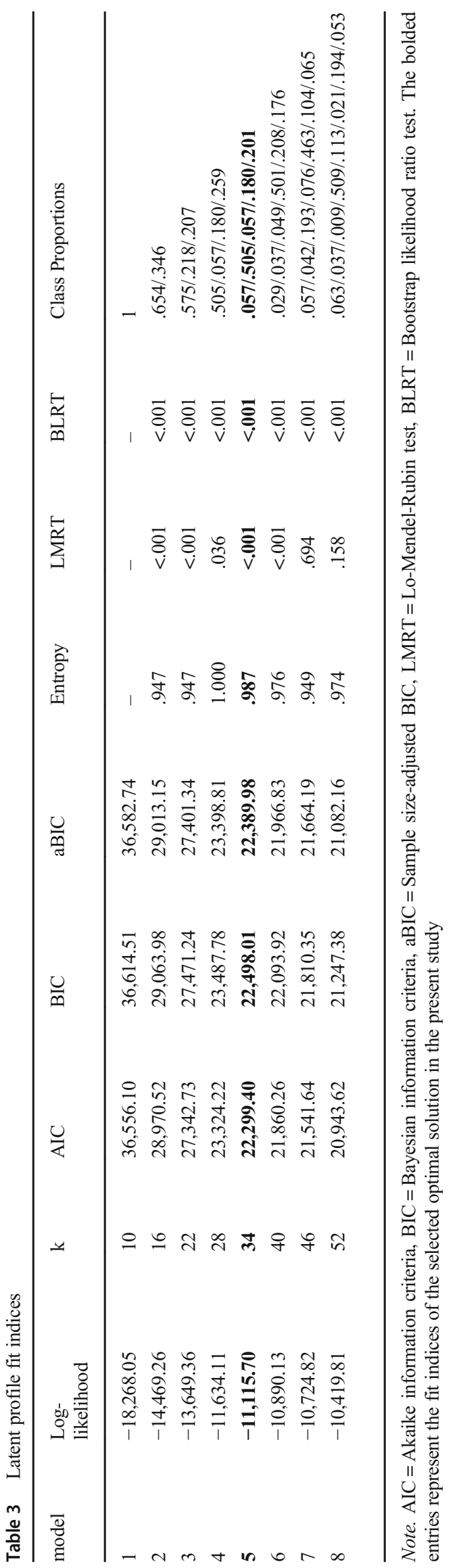


Figure 2 presented the five distinguished profiles: (1) lowest mean scores in all domains (worsened group; 5.66\%); (2) scores in five domains of life fluctuated slightly around 3 before and after the pandemic (unchanged group; 50.51\%); (3) the second highest mean scores in relationships (interparental and parent-adolescent), which were saliently better than personal status (relationship-improved group; $5.74 \%$ ); (4) relative high scores in both personal status (emotion, academic and regularity ranking second) and relational status (interparental and parent-adolescent relationship ranking third; moderately improved group; 17.96\%); (5) highest mean scores in all domains (largely improved group; $20.13 \%)$.

\section{Multinomial Logistic Regression}

Associations between predictors and five profiles were presented in Table 4, with unchanged group considered as the reference group. Among individual-level predictors, male gender predicted membership of moderately and largely improved groups. A younger age and more help-seeking behaviors predicted membership of improved groups. Higher levels of COVID-19 fears and lower levels of psychological distress predicted the membership of largely improved group, while higher levels of psychological distress predicted membership of moderately improved group.

In terms of familial-level predictors, almost all factors related to parents were not significantly associated with the membership of either group, except for COVID-19 fear of parents. For family interactions, parentadolescent conflict reported by adolescents predicted membership of all groups, while higher levels of conflict reported by parents only predicted membership of worsened group. Moreover, adolescents who reported lower levels of perceived interparental conflict were more likely to be in largely improved group. In regard to general family climate, adolescents who perceived higher family economic status were more likely to be classified into largely improved group, while objective annual household income failed to predict classification. Besides, higher levels of home chaos predicted membership in worsened group.

For the societal-level predictors, higher levels of social support of adolescents could predict membership in largely improved group.

\section{Discussion}

To the best of our knowledge, this study is the first to examine various aspects of adolescent life changes under a significant worldwide event. Taking the COVID-19 pandemic as an opportunity, we identified different patterns of adolescent life changes across a wide range of aspects (i.e., relationships, emotion, academic, and life regulation) and examined whether multiple factors at individual, familial, and societal levels could distinguish the patterns based on the holisticinteractionistic perspective. Our findings may provide insight into similar global threats, including the subsequent wave of COVID-19 and other infectious disease outbreaks or potentially natural disasters in the future (World Economic Forum, 2019).

\section{The Nature of Profiles}

Analyses revealed five distinct life change profiles, including three improved groups (relationship-improved group, moderately improved group, and largely improved group), one worsened group, and one unchanged group. Roughly half of participants fell into unchanged group, and the majority of the remainder fell into improved group. An encouraging finding is that only about $5 \%$ of adolescent life went worse after the
Fig. 2 Life change patterns across five domains of adolescent life during the COVID-19 pandemic

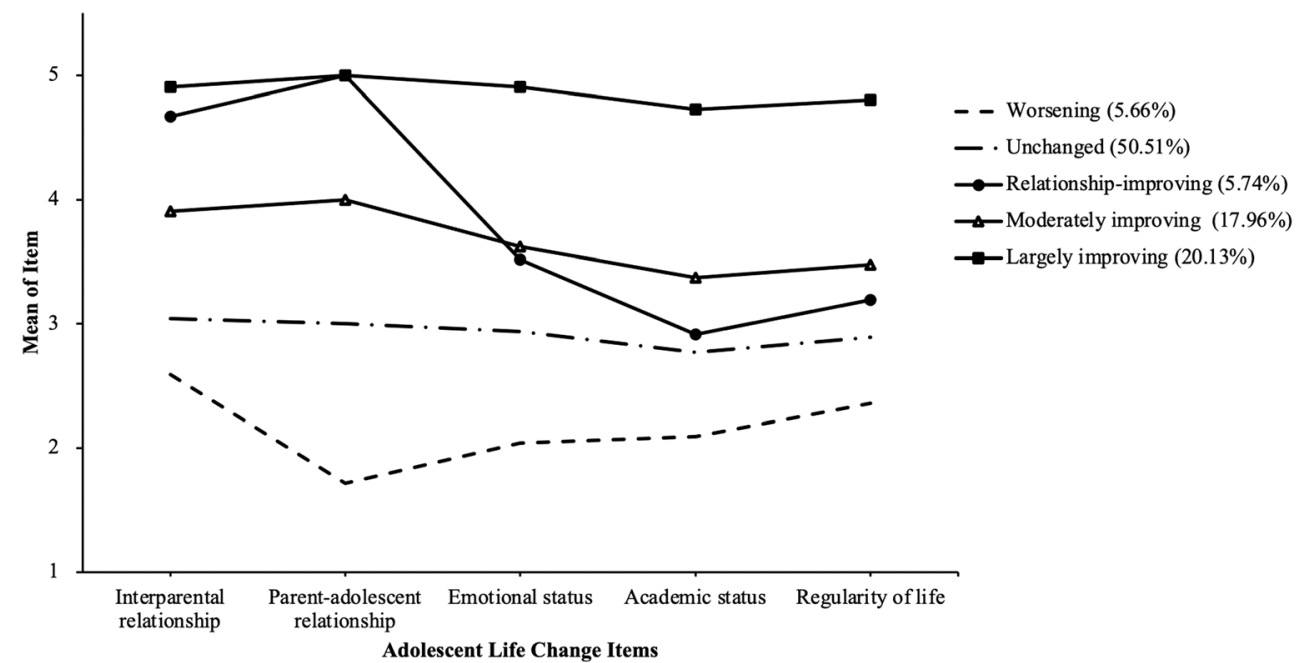


Table 4 R3STEP results predicting profile membership compared to the unchanged profile

\begin{tabular}{|c|c|c|c|c|c|c|c|c|}
\hline & \multicolumn{2}{|c|}{ Worsened } & \multicolumn{2}{|c|}{$\begin{array}{l}\text { Relationship- } \\
\text { improved }\end{array}$} & \multicolumn{2}{|c|}{$\begin{array}{l}\text { Moderately } \\
\text { improved }\end{array}$} & \multicolumn{2}{|c|}{$\begin{array}{l}\text { Largely } \\
\text { improved }\end{array}$} \\
\hline & ORs & $p$ & ORs & $p$ & ORs & $p$ & ORs & $p$ \\
\hline \multicolumn{9}{|l|}{ Individual level } \\
\hline Gender & 1.10 & 0.68 & 1.06 & 0.78 & 0.69 & $<.01$ & 0.68 & $<.01$ \\
\hline Age & 0.94 & 0.28 & 0.89 & 0.06 & 0.95 & 0.11 & 0.84 & $<.001$ \\
\hline COVID-19 fears & 0.99 & 0.64 & 1.04 & 0.05 & 1.01 & 0.27 & 1.04 & $<.01$ \\
\hline Psychological distress & 1.01 & 0.05 & 1.00 & 0.84 & 1.01 & $<.01$ & 0.97 & $<.001$ \\
\hline Help-seeking behavior & 1.01 & 0.92 & 1.09 & 0.03 & 1.07 & 0.01 & 1.16 & $<.001$ \\
\hline \multicolumn{9}{|l|}{ Familial level } \\
\hline \multicolumn{9}{|l|}{ Family members } \\
\hline Education_P & 0.94 & 0.60 & 1.19 & 0.13 & 1.01 & 0.88 & 1.04 & 0.64 \\
\hline COVID-19 fears_P & 0.96 & 0.04 & 1.00 & 0.94 & 1.00 & 0.99 & 1.00 & 0.88 \\
\hline Psychological distress_P & 1.00 & 0.51 & 1.01 & 0.30 & 0.99 & 0.17 & 1.00 & 0.49 \\
\hline Help-seeking behavior_P & 1.00 & 0.96 & 1.03 & 0.45 & 1.00 & 0.88 & 1.03 & 0.26 \\
\hline \multicolumn{9}{|l|}{ Family interactions } \\
\hline Parent-adolescent conflict & 2.02 & $<.001$ & 0.65 & 0.02 & 0.80 & 0.02 & 0.49 & $<.001$ \\
\hline Parent-adolescent conflict_P & 1.41 & 0.02 & 0.88 & 0.42 & 1.04 & 0.66 & 1.01 & 0.95 \\
\hline Perceived interparental conflict & 1.02 & 0.28 & 1.00 & 0.84 & 1.01 & 0.12 & 0.97 & $<.001$ \\
\hline Marital conflict_P & 0.99 & 0.70 & 0.97 & 0.28 & 1.02 & 0.16 & 0.98 & 0.35 \\
\hline \multicolumn{9}{|l|}{ General family climate } \\
\hline Perceived family economic status & 0.93 & 0.71 & 0.93 & 0.71 & 1.15 & 0.25 & 1.53 & $<.01$ \\
\hline Annual family income_P & 0.94 & 0.62 & 0.80 & 0.08 & 0.92 & 0.29 & 0.88 & 0.16 \\
\hline Per capita living area_P & 1.00 & 0.76 & 1.00 & 0.91 & 0.99 & 0.06 & 1.00 & 0.89 \\
\hline Home chaos & 1.08 & 0.05 & 1.05 & 0.32 & 0.98 & 0.47 & 1.08 & 0.07 \\
\hline \multicolumn{9}{|l|}{ Societal level } \\
\hline Social support & 0.91 & 0.58 & 1.28 & 0.31 & 1.18 & 0.18 & 1.88 & $<.001$ \\
\hline Social support_P & 1.13 & 0.49 & 1.11 & 0.57 & 1.04 & 0.72 & 0.96 & 0.73 \\
\hline
\end{tabular}

Note. Gender of the parent reporter and whether the parent reporter was the primary caregiver were considered as confounding variables

pandemic, which suggested that the negative impact of the pandemic that have been emphasized in previous studies only affected a small number of adolescents.

In contrast to expectations for hypothesis, we found a group only saliently improved in relationship (interparental and parent-child) while showed inconspicuous changes in individual aspects of life. A possible explanation is that the home confinement policy could increase the time spending with family members together and provide opportunities to enhance the interactions (G. Wang et al., 2020), leading to better relationships among family members. However, the increasing academic pressure led by increase in the quantity of homework might offset the spillover effect from the improved family relationship, so the personal status did not show significant improvement.

Previous research navigating the influences of the pandemic mainly applied a variable-centered research, in which researchers determined which aspect (i.e., negative or positive) to focus on. Mostly studies advocated the negative impact of the pandemic and focused on the negative influences of risk factors on adolescent functioning (G. Wang et al., 2020). However, using a person-centered approach, the present study revealed objective change patterns that apply to every case in the sample, which provides a revise and supplement to the traditional variable-centered perspective.

\section{Predictors of Adolescents' Life Change Patterns}

As hypothesized, the current study found that at least one targeted predictor at each three level effectively distinguished different patterns of changes. Additionally, findings provided insight into how multiple factors are differentially associated with different profiles. Notably, some predictors at individual and societal levels predicted improved life changes, while familial correlates predicted both improved and worsened life changes. The findings extended previous results by considering various sources of impacts simultaneously during a global crisis such as the COVID-19 pandemic. Familial-level factors, 
especially parent-child interaction, were proved to play pivotal roles in affecting adolescent lives.

\section{Individual Level}

Our study found that boys were more likely to experience better changes in life as compared to girls, which is consistent with previous findings ( $\mathrm{Li}$ et al., 2020). The stronger experience of emotions and higher rate of mental illness in women during the pandemic may be responsible for this risk in having a worse life change (Fu et al., 2020). In addition, consistent with previous research finding that older students are more vulnerable to internalizing problems (Zhou et al., 2020), we also found a lower possibility of having improved life changes in older adolescents. Two potential reasons may account for it: on the one hand, older adolescents are typically higher-graders who experience more psychological distress due to heavier workload and higher pressure, which may influence various aspects of life (Liu \& Lu, 2012). On the other, older adolescents tend to obtain a larger amount of information from social media which can easily trigger stress (Cheng et al., 2014; Qiu et al., 2020). Furthermore, more help-seeking behaviors also predicted a better life change. Help-seeking behaviors effectively help one to ease anxiety and build a mutual support network (Luo et al., 2020), thereby enriching psychological resources and leading to better life changes.

For pandemic-specific factors, psychological distress showed negative correlation with improved life changes, whereas COVID-19 fear positively related to an improved life. The characteristics of these two variables may interpret this difference. Psychological distress, representing general emotional, physical, and behavioral reactions towards stress in life, may lead to a general concern which is difficult to deal with. In contrast, as a situation-specific fear, COVID-19 fear is more of a functional and protective fear which helps raise concern and motivates one to get prepared for future negative stimuli (Harper et al., 2020). In fact, previous research has found that specific perceptions about the COVID-19 such as awareness of risks and fear for the pandemic positively predicted preventive behaviors, which may lead to better life changes (Harper et al., 2020; Wise et al., 2020). In the present study, participants showed a relatively low mean level (2.59 out of 5) of COVID-19 fear, which was more likely to alert individuals rather than exert negative influences on life.

\section{Familial Level}

Parental factors, family interactions, and general family climate showed different potential in distinguishing different patterns of life changes. Almost none of the parental factors predicted life change of adolescents, since parents may not talk about their concerns and fears with their children for fear of conveying their negative emotions to them.
In terms of family interactions, parent-adolescent conflict was correlated with all life change patterns and was thus considered as the most important factor influencing adolescent life changes. Adolescents who perceived lower levels of conflict with their parents tend to have better changes in life and vice versa. Consistent with Magson and her colleagues' (Magson et al., 2020) findings that increased conflict with parents during the pandemic moderated change in depressive symptoms and life satisfaction, our finding also emphasized the importance of the parent-adolescent interaction in influencing adolescent life during the pandemic. In addition, adolescents who perceived less interparental conflict were more likely to experience improved life changes, consistent with previous studies (Davies \& Cummings, 1994; Hudson, 2005).

As for the general family climate, the current research found that higher family chaos was more likely to predict negative life changes. This result aligned well with the Emotional Security Theory (Davies \& Cummings, 1994) which proposed that broader family contexts could go beyond parental interactions in influencing children well-being. In a chaotic family, parents may be less responsive and have less positive reactions toward adolescents, which may harm their well-being and lead to a worsened life (Fiese \& Winter, 2010)..

In addition, higher subjective but not objective economic status was associated with improved life changes, which is consistent with previous finding that subjective instead of objective family economic status predicted individual's health and life quality (Choi et al., 2015; Präg, 2020). The labor market shock may cause unemployment in plenty of families during the pandemic and lower income families may be especially influenced, since they are not able to deal with unemployment and related outcomes (Brewer \& Gardiner, 2020)..

\section{Societal Level}

Adolescents who perceived more social support were found more likely to have better life changes. According to the Salutogenic Model (Idan et al., 2017) and the stress-buffering hypothesis (Cohen \& Pressman, 2004), perceived social support is an important general resistance resource to protect and even enhance one's health in stressful situations. Accordingly, recent studies have also found positive association between perceived social support and individual adjustments (Cao et al., 2020; Ni et al., 2020). Indeed, Chinese citizens received multiple resources of social support during the pandemic. A strong quarantine policy was implemented to stop the virus from spreading so that the pandemic was successfully controlled within 2 months (Bureau of Disease Prevention and Control, 2020). In addition, many communities organized online and offline activities (e.g., tai-chi, chorus) that built connection among people. Moreover, Chinese government 
opened over 300 psychological assistance hotlines in all provinces (Central People's Government of the People's Republic of China, 2020) to provide professional and effective help for the public. These social resources might make individuals perceive more support and help them ease stress, leading to better life changes.

This study verified the three-level model proposed under the holistic-interactionistic perspective by demonstrating factors in three levels could impact adolescent life during the unprecedented global COVID-19 pandemic. Particularly, we highlighted the importance of family in affecting adolescent lives, especially during situations characterized by uncontrollable threats (e.g., pandemics, natural disasters). For future research, special attention should be paid to familial factors, especially parent-adolescent interaction. In addition, we also examined COVID-19 related factors (e.g., fear of COVID-19 and help-seeking behaviors) and verified their effectiveness in predicting adolescent life change patterns.

In practice, this study identified vulnerable subgroups in such a global crisis as the COVID-19 pandemic and examined factors that needs intervention in order to improve adolescent lives. Firstly, this study provided insight in identifying adolescents who are at greatest risk for negative life changes or are less possible for positive life changes during the macro-level crisis. Students who are female, at higher-grade, in lower subjective economic status deserved most focus and intervention. Secondly, several key factors (e.g., actively seeking for support, improving family warmth, etc.) have been identified in the present study to offer possibilities for changing to a better life, relieve individuals' psychological distress and enhance their well-being during the pandemic. To help adolescents relieve distress and enhance well-being under the social-distancing policy, Internet-based psychoeducation and intervention are needed. For example, by teaching individuals cognitive and behavioral techniques to combat psychological distress and to form adaptive coping strategies, Internet-delivered cognitive behavioral therapy (ICBT) has been confirmed to be effective in decreasing individuals' depression, anxiety, and stress under the COVID-19 pandemic (Aminoff et al., 2021; Ho et al., 2020). Thirdly, as mobile phones have been widely popularized among adolescents, integrating pandemic-related supportive functions (e.g., introducing epidemic prevention knowledge) into mobile applications that are popular with adolescents (e.g., QQ, Wechat, Bilibili in China; Snapchat, Instagram, Facebook in the US) will also help adolescents deal with pandemic-related stress (Zhang et al., 2021).

Several limitations of this study should also be noted. Firstly, due to the home confinement policy, the data had to be collected via online questionnaire, causing lack of monitor on the state of participants when answering the questionnaires. Secondly, although some data were collected from multiple reporters, we examined their influences on life change independently. As a result, the methodological limitation of self- report still exists. Another potential limitation of our study is concerns about causality. Due to the unpredictability of this global pandemic, it is nearly impossible to track adolescent life changes before the outbreak. Using a cross-sectional design, this study is unable to directly assess the fluctuation of life before and after the pandemic. For example, in the "unchanged group", it is unlikely to differentiate individuals whose life is consistently better than average from those whose life is consistently worse than average. Future studies may benefit from using a longitudinal design and the latent growth curve model to further explore the patterns of life change and antecedents of different patterns. Lastly, mother and father played different roles in adolescent development (Collins \& Laursen, 2004; van Lissa \& Keizer, 2020). However, given that only one of adolescents' parents were asked to fill in the questionnaire ( $74.8 \%$ were mothers), the present study did not differentiate paternal and maternal influences on adolescent life changes. It would be intriguing to invite fathers, mothers, and other family members to participate in the study to examine the influences of different family members and their interactions.

With the increase of knowledge about the novel coronavirus, many countries have made great progress in developing COVID-19 vaccines. By the end of June, over 250 vaccines were in clinical or pre-clinical development (World Health Organization, 2021a), and over 2.9 billion doses of vaccine have already been administered worldwide (World Health Organization, 2021b). The rapid development and administration of vaccines is considered to be a great step forward in controlling contagion, however, vaccine hesitancy may largely prevent us from combating the pandemic, which was listed as one of the ten biggest health threats in 2019 (World Health Organization, 2019). Research has shown that views on vaccine safety, financial concerns, and stigmatization to the vaccine are significantly associated with the willingness to receive the COVID-19 vaccination in healthcare workers (Chew et al., 2021). It is important for future research to discover how these factors as well as other individual, familial, and societal factors under the holistic-interactionistic perspective would influence and enhance the willingness to vaccinate in adolescents.

\section{Conclusion}

To the best of our knowledge, this study is the first to examine the patterns of life changes and their correlates within a large Chinese adolescent sample during a global public health crisis. The findings indicated five profiles of adolescent life changes during the pandemic, including three improved, one unchanged, and one worsened. The majority of adolescents had better life changes or remained unchanged. Besides, factors at the individual, familial, and societal levels had unique 
contributions to adolescent life changes. The pivotal role of family may be particularly highlighted under the circumstances of COVID-19 pandemic; specifically, adolescentparent interaction was essentially influential to adolescent life during the pandemic. Since that it is still unclear how long the pandemic will persist and there is still much to be understood about the impact of the current pandemic, the present study offered critical insights into adolescents' life changes during the initial phases of this crisis and provided suggestions on prevention and intervention strategies to promote adolescent life quality.

Code Availability Not applicable.

Author's Contributions JS, JX and XF conceptualized the idea and formulated the research goals and hypotheses. WL and HL collected the data. JS and YD performed the analyses. XF supervised the research. JS and RS wrote the manuscript and all authors provided feedback and approved the final version of the paper.

Funding This work was supported by Mercedes-Benz Star Fund and Tencent Foundation (Grant number 600185).

Data Availability The data that support the findings of this study are available from the corresponding author on reasonable request.

\section{Declarations}

Conflict of Interest The authors declare that they have no competing interests.

Ethics Approval Approval was obtained from the ethics committee of Beijing Normal University.

Consent to Participate Informed consent was obtained from all individual participants included in the study.

\section{References}

Ahorsu, K. D., Lin, C. Y., Imani, V., Saffari, M., Griffiths, M. D., \& Pakpour, A. H. (2020). The fear of COVID-19 scale: Development and initial validation. International Journal of Mental Health and Addiction. https://doi.org/10.1007/s11469-02000270-8

Amerio, A., Brambilla, A., Morganti, A., Aguglia, A., Bianchi, D., Santi, F., Costantini, L., Odone, A., Costanza, A., Signorelli, C., Serafini, G., Amore, M., \& Capolongo, S. (2020). COVID-19 lockdown: Housing built environment's effects on mental health. International Journal of Environmental Research and Public Health, 17(16), 5973

Aminoff, V., Sellén, M., Sörliden, E., Ludvigsson, M., Berg, M., \& Andersson, G. (2021). Internet-based cognitive behavioral therapy for psychological distress associated with the COVID-19 pandemic: A pilot randomized controlled trial. Frontiers in Psychology, 12, 1998

Asparouhov, T., \& Muthén, B. (2014). Auxiliary variables in mixture modeling: Three-step approaches using M plus. Structural Equation Modeling: A Multidisciplinary Journal, 21(3), 329-341
Baltes, P. B., Reese, H. W., \& Lipsitt, L. P. (1980). Life-span developmental psychology. Annual Review of Psychology, 31(1), 65-110

Bámaca-Colbert, M. Y., Umaña-Taylor, A. J., \& Gayles, J. G. (2012). A developmental-contextual model of depressive symptoms in Mexican-origin female adolescents. Developmental Psychology, 48(2), 406-421

Barros, J. M., Duggan, J., \& Rebholz-Schuhmann, D. (2020). The application of internet-based sources for public health surveillance (Infoveillance): Systematic review. Journal of Medical Internet Research, 22(3), e13680

Becker, S. P., Breaux, R., Cusick, C. N., Dvorsky, M. R., Marsh, N. P., Sciberras, E., \& Langberg, J. M. (2020). Remote learning during COVID-19: Examining school practices, service continuation, and difficulties for adolescents with and without attention deficit/hyperactivity disorder. Journal of Adolescent Health, 67(6), 769-777

Bradford, K., Vaughn, L. B., \& Barber, B. K. (2008). When there is conflict: Interparental conflict, parent-child conflict, and youth problem behaviors. Journal of Family Issues, 29(6), 780-805

Brewer, M., \& Gardiner, L. (2020). The initial impact of COVID-19 and policy responses on household incomes. Oxford Review of Economic Policy, 36, S187-S199

Bronfrenbrenner, U. (1979). Contexts of child rearing: Problems and prospects. American Psychologist, 34(10), 844-850

Brooks, S. K., Webster, R. K., Smith, L. E., Woodland, L., Wessely, S., Greenberg, N., \& Rubin, G. J. (2020). The psychological impact of quarantine and how to reduce it: Rapid review of the evidence. The Lancet, 395(10227), 912-920

Browne, D. T., Plamondon, A., Prime, H., Puente-Duran, S., \& Wade, M. (2015). Cumulative risk and developmental health: An argument for the importance of a family-wide science. Wiley Interdisciplinary Reviews: Cognitive Science, 6(4), 397-407

Bureau of Disease Prevention and Control. (2020). Notice on the strict prevention of the novel coronavirus infection through transportation. h t t p://ww w.nhc.gov.cn/jkj/s $3577 / 202001 /$ e5e8c983baba4c1589512e6c99fdaa4e.shtml

Butcher, L. M., \& Plomin, R. (2008). The nature of nurture: A genomewide association scan for family chaos. Behavior Genetics, 38(4), 361-371

Cao, W., Fang, Z., Hou, G., Han, M., Xu, X., Dong, J., \& Zheng, J. (2020). The psychological impact of the COVID-19 epidemic on college students in China. Psychiatry Research, 287, 112934

Central People's Government of the People's Republic of China. (2020). During the epidemic period, 24-hour psychological assistance hotline was opened all over the country. http://www.gov.cn/fuwu/ 2020-02/05/content 5474792.htm

Chaplin, T. M., Sinha, R., Simmons, J. A., Healy, S. M., Mayes, L. C., Hommer, R. E., \& Crowley, M. J. (2012). Parent-adolescent conflict interactions and adolescent alcohol use. Addictive Behaviors, 37(5), 605-612

Chen, S., Yang, J., Yang, W., Wang, C., \& Bärnighausen, T. (2020). COVID-19 control in China during mass population movements at new year. The Lancet, 395(10226), 764-766

Cheng, C., Huang, J., \& Liang, B. (2014). Psychological health diathesis assessment system: A nationwide survey of resilient trait scale for Chinese adults. Studies of Psychology and Behavior, 12(6), 735742

Chew, N. W., Cheong, C., Kong, G., Phua, K., Ngiam, J. N., Tan, B. Y., Wang, B., Hao, F., Tan, W., Han, X., Tran, B. X., Hoang, M. T., Pham, H. Q., Vu, G. T., Chen, Y., Danuaji, R., Rn, K., Pv, M., Talati, K., et al. (2021). An Asia-Pacific study on healthcare workers' perceptions of, and willingness to receive, the COVID19 vaccination. International Journal of Infectious Diseases, 106, $52-60$

Choi, Y., Kim, J. H., \& Park, E. C. (2015). The effect of subjective and objective social class on health-related quality of life: New paradigm 
using longitudinal analysis. Health and Quality of Life Outcomes, 13, 1-11

Cohen, S., \& Pressman, S. (2004). Stress-buffering hypothesis. In N. B. Anderson (Ed.), Encyclopedia of health and behavior (pp. 696697). SAGE Publications

Collins, L. M., \& Lanza, S. T. (2010). Latent class and latent transition analysis: With applications in the social, behavioral and health sciences. Wiley

Collins, W. A., \& Laursen, B. (2004). Parent-adolescent relationships and influences. In R. M. Lerner \& L. Steinberg (Eds.), Handbook of adolescent psychology, (2 ed., pp. 331-362). John Wiley \& Sons Inc

Crum, K. I., \& Moreland, A. D. (2017). Parental stress and children's social and behavioral outcomes: The role of abuse potential over time. Journal of Child and Family Studies, 26(11), 3067-3078

Davies, P. T., \& Cummings, E. M. (1994). Marital conflict and child adjustment: An emotional security hypothesis. Psychological Bulletin, 116(3), 387-411

Davies, P. T., Harold, G. T., Goeke-Morey, M., \& Cummings, E. M. (2002). Child emotional security and interparental conflict. Monographs of the Society for Research in Child Development, 67(3), 1-129

Davis-Kean, P. (2005). The influence of parent education and family income on child achievement: The indirect role of parental expectations and the home environment. Journal of Family Psychology, 19(2), 294-304

Drouin, M., McDaniel, B. T., Pater, J., \& Toscos, T. (2020). How parents and their children used social media and technology at the beginning of the COVID-19 pandemic and associations with anxiety. Cyberpsychology, Behavior and Social Networking, 23(11), 727736

Ermisch, J., \& Francesconi, M. (2001). Family matters: Impacts of family background on educational attainments. Economica, 68(270), 137156

Fiese, B. H., \& Winter, M. A. (2010). The dynamics of family chaos and its relation to children's socioemotional well-being. In G. W. Evans $\&$ T. D. Wachs (Eds.), Chaos and its influence on children's development: An ecological perspective (pp. 49-66). American Psychological Association

Fu, W., Wang, C., Zou, L., Guo, Y., Lu, Z., Yan, S., \& Mao, J. (2020). Psychological health, sleep quality, and coping styles to stress facing the COVID-19 in Wuhan, China. Translational Psychiatry, 10(1), $1-9$

Giano, Z., Currin, J. M., Deboy, K., \& Hubach, R. D. (2020). Identifying distinct subgroups of lesbian, gay, and bisexual youth for suicide risk: A latent profile analysis. Journal of Adolescent Health, 67(2), 194-200

Grych, J. H., Seid, M., \& Fincham, F. D. (1992). Assessing marital conflict from the Child's perspective: The Children's perception of Interparental conflict scale. Child Development, 63(3), 558-572

Gudicha, D. W., \& Vermunt, J. K. (2013). Mixture model clustering with covariates using adjusted three-step approaches. In B. Lausen, D. Van den Poel, \& A. Ultsch (Eds.), Algorithms from and for nature and life., studies in classification, data analysis, and knowledge organization (pp. 87-94). Springer

Hall, G. S. (1904). Adolescence: Its psychology and its relation to physiology, anthropology, sociology, sex, crime, religion, and education (Vols. I \& II). Prentice-Hall

Harper, C. A., Satchell, L. P., Fido, D., \& Latzman, R. D. (2020). Functional fear predicts public health compliance in the COVID19 pandemic. International Journal of Mental Health and Addiction, 1-14. https://doi.org/10.1007/s11469-020-00281-5

Haslam, C., Haslam, S. A., Jetten, J., Cruwys, T., \& Steffens, N. K. (2020). Life change, social identity, and health. Annual Review of Psychology, 72, 635-661

Hawke, L. D., Barbic, S., Voineskos, A., Szatmari, P., Cleverley, K., Hayes, E., Relihan, J., Daley, M., Courtney, D., Cheung, A.,
Darnay, K., \& Henderson, J. L. (2020). Impacts of COVID-19 on youth mental health, substance use, and well-being: A rapid survey of clinical and community samples. The Canadian Journal of Psychiatry, 65(10), 701-709

Hinde, R. A. (1992). Developmental psychology in the context of other behavioral sciences. Developmental Psychology, 28(6), 1018-1029.

Ho, C. S., Chee, C. Y., \& Ho, R. C. (2020). Mental health strategies to combat the psychological impact of COVID-19 beyond paranoia and panic. Annals of the Academy of Medicine, Singapore, 49(1), $1-3$

Hudson, J. L. (2005). Interparental conflict, violence and psychopathology. In J. L. Hudson \& R. M. Rapee (Eds.), Psychopathology and the family (pp. 53-69). Elsevier Science

Idan, O., Eriksson, M., \& Al-Yagon, M. (2017). The salutogenic model: The role of generalized resistance resources. In M. B. Mittelmark, S. Sagy, M. Eriksson, G. Bauer, J. M. Pelikan, B. Lindström, \& G. A. Espnes (Eds.), The handbook of Salutogenesis (pp. 57-69). Springer Publishers

Johnson, V. K., Cowan, P. A., \& Cowan, C. P. (1999). Children's classroom behavior: The unique contribution of family organization. Journal of Family Psychology, 13(3), 355-371

Jung, T., \& Wickrama, K. A. S. (2008). An introduction to latent class growth analysis and growth mixture modeling. Social and Personality Psychology Compass, 2(1), 302-317

Katz, B. A., \& Yovel, I. (2020). Mood symptoms predict COVID-19 pandemic distress but not vice versa: An 18-month longitudinal study. Psyarvix. https://psyarxiv.com/6qske/

Li, J., Yang, A., Dou, K., Wang, L., Zhang, M., \& Lin, X. (2020). Chinese public's knowledge, perceived severity, and perceived controllability of the COVID-19 and their associations with emotional and behavioural reactions, social participation, and precautionary behaviour: A national survey. BMC Public Health, 20, 1589

Liu, Y., \& Lu, Z. (2012). Chinese high school students' academic stress and depressive symptoms: Gender and school climate as moderators. Stress and Health, 28(4), 340-346

Luo, C., Li, Y., Chen, A., \& Tang, Y. (2020). What triggers online helpseeking retransmission during the COVID-19 period? Empirical evidence from Chinese social media. PLoS One, 15(11), e0241465

Magnusson, D., \& Stattin, H. (1998). Person-context interaction theories. In W. Damon \& R. M. Lerner (Eds.), Handbook of child psychology: Theoretical models of human development (5 ed., pp. 685-759). John Wiley \& Sons Inc.

Magnusson, D., \& Stattin, H. (2006). The person in context: A holisticinteractionistic approach. In W. Daimon \& R. M. Lerner (Eds.), Handbook of child psychology: Theoretical models of human development (6 ed., pp. 400-464). John Wiley \& Sons Inc.

Magson, N. R., Freeman, J. Y. A., Rapee, R. M., Richardson, C. E., Oar, E. L., \& Fardouly, J. (2020). Risk and protective factors for prospective changes in adolescent mental health during the COVID-19 pandemic. Journal of Youth and Adolescence, 50(1), 44-57

Mancini, A. D. (2019). When acute adversity improves psychological health: A social-contextual framework. Psychological Review, $126(4), 486-505$

Mancini, A. D. (2020). Heterogeneous mental health consequences of COVID-19: Costs and benefits. Psychological Trauma:Theory, Research, Practice, and Policy, 12, S15-S16

Marsh, S., Dobson, R., \& Maddison, R. (2020). The relationship between household chaos and child, parent, and family outcomes:A systematic scoping review. BMC Public Health, 20, 1-27

Matheny, A. P., Wachs, T. D., Ludwig, J. L., \& Phillips, K. (1995). Bringing order out of Chaos: Psychometric characteristics of the confusion, hubbub, and order scale. Journal of Applied Developmental Psychology, 16, 429-444

Minuchin, P. (1985). Families and individual development: Provocations from the field of family therapy. Child Development, 56(2), 289302 
Morgeson, F. P., Mitchell, T., \& Liu, D. (2015). Event system theory: An event-oriented approach to the organizational sciences. Academy of Management Review, 40, 515-537

Ni, M. Y., Yang, L., Leung, C. M., Li, N., Yao, X. I., Wang, Y., Leung, G. M., Cowling, B. J., \& Liao, Q. (2020). Mental health, risk factors, and social media use during the COVID-19 epidemic and cordon sanitaire among the community and health professionals in Wuhan, China: Cross-sectional survey. JMIR Mental Health, 7(5), e19009

Ornell, F., Schuch, J. B., Sordi, A. O., \& Kessler, F. H. P. (2020). "Pandemic fear" and COVID-19: Mental health burden and strategies. Brazilian Journal of Psychiatry, 42(3), 232-235

Präg, P. (2020). Subjective socio-economic status predicts self-rated health irrespective of objective family socio-economic background. Scandinavian Journal of Public Health, 48(7), 707-714

Prime, H., Wade, M., \& Browne, D. T. (2020). Risk and resilience in family well-being during the COVID-19 pandemic. American Psychologist, 75(5), 631-643

Putri, R. S., Purwanto, A., Pramono, R., Asbari, M., Wijayanti, L. M., \& Hyun, C. C. (2020). Impact of the COVID-19 pandemic on online home learning: An explorative study of primary schools in Indonesia. International Journal of Advanced Science and Technology, 29(5), 4809-4818

Qiu, J., Shen, B., Zhao, M., Wang, Z., Xie, B., \& Xu, Y. (2020). A nationwide survey of psychological distress among Chinese people in the COVID-19 epidemic: Implications and policy recommendations. General Psychiatry, 33(2), 1-2

Ravens-Sieberer, U., Kaman, A., Erhart, M., Devine, J., Schlack, R., \& Otto, C. (2021). Impact of the COVID-19 pandemic on quality of life and mental health in children and adolescents in Germany. European Child \& Adolescent Psychiatry, 1-11. https://doi.org/10. 1007/s00787-021-01726-5

Richmond, M. K., \& Stocker, C. M. (2006). Associations between family cohesion and adolescent siblings' externalizing behavior. Journal of Family Psychology, 20(4), 663-669

Russell, B. S., Hutchison, M., Tambling, R., Tomkunas, A. J., \& Horton, A. L. (2020). Initial challenges of caregiving during COVID-19: Caregiver burden, mental health, and the parent-child relationship. Child Psychiatry \& Human Development, 51(5), 671-682

Satici, B., Gocet-Tekin, E., Deniz, M. E., \& Satici, S. A. (2020). Adaptation of the fear of COVID-19 scale: Its association with psychological distress and life satisfaction in Turkey. International journal of mental health and addiction, 1-9. https://doi.org/10.1007/ s11469-020-00294-0

Shapero, B. G., \& Steinberg, L. (2013). Emotional reactivity and exposure to household stress in childhood predict psychological problems in adolescence. Journal of Youth and Adolescence, 42(10), $1573-1582$

Shigemura, J., Ursano, R. J., Morganstein, J. C., Kurosawa, M., \& Benedek, D. M. (2020). Public responses to the novel 2019 coronavirus (2019-nCoV) in Japan: Mental health consequences and target populations. Psychiatry and Clinical Neurosciences, 74(4), 281282

Spanier, G. B. (1976). Measuring dyadic adjustment: New scale for assessing the quality of marriage and similar dyads. Journal of Marriage and the Family, 38(1), 15-28

Steeger, C. M., \& Gondoli, D. M. (2013). Mother-adolescent conflict as a mediator between adolescent problem behaviors and maternal psychological control. Developmental Psychology, 49(4), 804-814

Van Lissa, C. J., \& Keizer, R. (2020). Mothers' and fathers' quantitative and qualitative parenting in relation to children's emotional adjustment: A between- and within-family investigation. Developmental Psychology, 56(9), 1709-1722

Vermunt, J. K. (2010). Latent class modeling with covariates: Two improved three-step approaches. Political Analysis, 18(4), 450-469

Wanberg, C. R., Csillag, B., Douglass, R. P., Zhou, L., \& Pollard, M. S. (2020). Socioeconomic status and well-being during COVID-19: A resource-based examination. Journal of Applied Psychology, 105(12), 1382-1396

Wang, C., Pan, R., Wan, X., Tan, Y., Xu, L., Ho, C. S., \& Ho, R. C. (2020a). Immediate psychological responses and associated factors during the initial stage of the 2019 coronavirus disease (COVID-19) epidemic among the general population in China. International Journal of Environmental Research and Public Health, 17(5), 1729

Wang, C., Pan, R., Wan, X., Tan, Y., Xu, L., McIntyre, R. S., Choo, F. N., Tran, B., Ho, R., Sharma, V. K., \& Ho, C. (2020b). A longitudinal study on the mental health of general population during the COVID-19 epidemic in China. Brain, Behavior, and Immunity, 87, $40-48$

Wang, G., Zhang, Y., Zhao, J., Zhang, J., \& Jiang, F. (2020c). Mitigate the effects of home confinement on children during the COVID-19 outbreak. The Lancet, 395(10228), 945-947

Wang, X., Lei, S. M., Le, S., Yang, Y., Zhang, B., Yao, W., Guo, Z., \& Cheng, S. (2020d). Bidirectional influence of the COVID-19 pandemic lockdowns on health behaviors and quality of life among Chinese adults. International Journal of Environmental Research and Public Health, 17(15), 5575

Wang, Z., Luo, S., Xu, J., Wang, Y., Yun, H., Zhao, Z., Zhan, H., \& Wang, Y. (2021). Well-being reduces COVID-19 anxiety: A threewave longitudinal study in China. Journal of Happiness Studies, 117. https://doi.org/10.1007/s10902-021-00385-2

Whittle, S., Bray, K., Lin, S., \& Schwartz, O. (2020). Parenting and child and adolescent mental health during the COVID-19 pandemic. PsyArXiv. https://doi.org/10.31234/osf.io/8h3v5

Wise, T., Zbozinek, T. D., Michelini, G., Hagan, C. C., \& Mobbs, D. (2020). Changes in risk perception and protective behavior during the first week of the COVID-19 pandemic in the United States. Royal Society Open Science, 7(9). https://doi.org/10.1098/rsos. 200742

Woo, S. E., Jebb, A. T., Tay, L., \& Parrigon, S. (2018). Putting the "person" in the center: Review and synthesis of person centered approaches and methods in organizational science. Organizational Research Methods, 21, 814-845

World Economic Forum. (2019). Outbreak readiness and business impact: Protecting lives and livelihoods across the global economy. Retrieved from http://www3.weforum.org/docs/WEFHGHI_ Outbreak Readiness- Business Impact.pdf

World Health Organization. (2019). Ten threats to global health in 2019. Retrieved July 2, 2021, from https://www.who.int/newsroom/ spotlight/ten-threats-to-global-health-in-2019

World Health Organization. (2021a). COVID-19 vaccine tracker and landscape. Retrieved July 4, 2021, from https://www.who.int/ publications/m/item/draft-landscape-of-covid-19-candidatevaccines

World Health Organization. (2021b). WHO Coronavirus (COVID-19) Dashboard. Retrieved July 4, 2021, from https://covid19.who.int/

Xiang, M., Zhang, Z., \& Kuwahara, K. (2020). Impact of COVID-19 pandemic on children and adolescents' lifestyle behavior larger than expected. Progress in Cardiovascular Diseases, 63(4), 531-532

Xiao, S. (1994). The theoretical basis and application for social support rating scale. Journal of Clinical Psychiatry, 4(2), 98-100

Xu, J., Ou, J., Luo, S., Wang, Z., Chang, E., Novak, C., Shen, J., Zheng, S., \& Wang, Y. (2020). Perceived social support protects lonely people against COVID-19 anxiety: A three-wave longitudinal study in China. Frontiers in Psychology, 11, 2759-2770

Zemp, M., Johnson, M. D., \& Bodenmann, G. (2019). Out of balance? Positivity-negativity ratios in couples' interaction impact child adjustment. Developmental Psychology, 55(1), 135-147

Zhang, M. W., Chow, A., Ho, R., \& Smith, H. E. (2021). An overview of commercially available apps in the initial months of the covid-19 pandemic. Frontiers in Psychiatry, 12, 424-430 
Zhong, X., Jiang, G., Wu, Z., \& Qian, L. (2004). Effect of life events, social support, stress response on coping style in medical personnel. Chinese Journal of Behavioral Medical Science, 13(5), 560-562

Zhou, S. J., Zhang, L. G., Wang, L. L., Guo, Z. C., Wang, J. Q., Chen, J. C., Liu, M., Chen, X., \& Chen, J. X. (2020). Prevalence and sociodemographic correlates of psychological health problems in Chinese adolescents during the outbreak of COVID-19. European Child \& Adolescent Psychiatry, 29(6), 749-758
Zou, H., Qu, Z., \& Ye, Y. (2007). The characteristics of teacher-student relationships and its relationship with school adjustment of student. Psychological Development and Education, 23(4), 77-82

Publisher's Note Springer Nature remains neutral with regard to jurisdictional claims in published maps and institutional affiliations. 